\title{
Introduction to the Special Section: Nightmares of Trauma Victims-Cross-cultural Perspectives
}

\author{
Devon E. Hinton
}

Published online: 20 February 2009

(C) Springer Science+Business Media, LLC 2009

Dream interpretation across cultures has been the subject of important studies, for example, the books edited by Lohmann (2003) and Mageo (2003). Those studies indicate that often dreams play an important role in identity formation and local psychologies; act as important self-processes, as in the case of "selfscape dreams" (Hollan 2003); result in ritual actions; hold a central place in the conceptualization of the relationship of the living to supernatural beings and the dead; and serve as a key indicator of physical and spiritual health. But trauma-related dreams have been minimally examined in cross-cultural perspective, and many questions are yet to be answered.

Some of these questions might include the following: Does trauma result in nightmares in other cultures? How does the interpretation of trauma-related dreams vary across cultures? How is the interpretation of nightmares related to the more general system of dream interpretation in that culture, the local oneirology? Does the content of trauma nightmares vary across cultures? In these other cultures, do the nightmares following a trauma consist of the reliving of the original trauma event? Are reliving dreams thought to be the most upsetting nightmares after a trauma, or are other types of dreams, such as those that indicate one to be in a physically or spiritually vulnerable state, more upsetting? In other cultures, how are trauma-related nightmares thought to be generated? Are specific treatments indicated for someone having nightmares, and if so, what are the effects of those treatments on recovery from trauma? In other cultures, is a nightmare discussed in the family or with others, leading to interpersonal and other effects? In other cultures, are trauma-caused nightmares a more salient part of the presentation of

\author{
D. E. Hinton $(\bowtie)$ \\ Psychiatry Department, Harvard Medical School, Boston, MA 02115, USA \\ e-mail: devon_hinton@hms.harvard.edu \\ D. E. Hinton \\ Massachusetts General Hospital, 15 Parkman Street, WACC 812, Boston, MA 02114, USA
}


trauma-related disorder? Is the rate of nightmares the same for different cultural groups given a similar degree of trauma? To put such questions more generally, does the culturally variable nature of trauma-related nightmares-on the level of meaning, indicated treatment, interpersonal effects-result in radically different trauma ontologies?

The trauma-related symptoms listed in the fourth edition of the Diagnostic and Statistical Manual (DSM-IV; American Psychiatric Association 1994) are not invariant across cultures, social groups, historical periods or even individuals. Elsewhere we refer to the mistake of assuming that a symptom's meaning-as in associated metaphors, trauma associations and local ideas about how the symptom is generated and what must be done to alleviate it-is the same across such contexts as being a "symptom fallacy," one form of the "category fallacy" (Hinton et al. 2007), what might also be called a "symptom error." Two persons from different cultures may even have a nightmare with almost-identical content, as in being chased, but the meaning of the dream, related interpretive processes and indicated practices will vary greatly. Only by examining a symptom in context will a symptom fallacy-that is, assuming a similarity between two symptoms when major differences exist-be avoided.

Between cultures, there is substantial similitude between symptoms when taken at a great level of abstraction: when a symptom is simply labeled as "nightmare." This might be called an "abstraction error," that is, finding a similarity between entities at the most abstract level and then claiming the two to be essentially identical. But upon scrutiny in context, great differences may well emerge: differences in the semantic networks, as well as associated practices, will become evident (Good 1994). Put another way, when one discovers that a symptom listed in the DSM-IV post-traumatic stress disorder (PTSD) criteria is common in a certain traumatized group, the next step in analysis must be the investigation of the symptom schema (Hinton et al. 2008; Kirmayer 1996)-taken in the broad sense, ranging from metaphor, to indicated practices, to interpersonal meanings and consequences - in that cultural context.

If nightmares are a key aspect of the trauma ontology (Hartmann 1998), a study of nightmares in cultural context is an important way of determining cross-cultural variation in trauma ontology. Nightmares are a key part of the reticulum that unites the traumatic events, conceptions of personhood, ideas about the supernatural, social relationships, personal experience and the body, what might be called the traumasomatic reticulum [cf. Kleinman's notion of the sociosomatic reticulum (Kleinman and Kleinman 1985)]. Such investigations might be said to pertain to traumasomatics, the study of the way in which trauma results in particular symptoms, of the cultural and social processes that link trauma, personal experience and somatic symptoms [cf. Kleinman's notion of the sociosomatics (Kleinman and Kleinman 1985)]. Only through a delineation of the trauma-somatic reticulum can the experience of trauma-and how healing might be facilitated-be sensitively understood.

The current special section is an examination of the role of nightmare in the trauma-somatic reticulum of several cultures. The articles investigate nightmares, including local systems of interpretation and associated practices, in several 
different groups: Spanish speakers, Indonesians, Cambodian refugees. We believe that this research agenda of investigating specific dimensions of what are perceived to be universal aspects of trauma-related disorder-as enshrined in the DSM-IV diagnostic criteria for PTSD_will lead to a greater appreciation of the cultural variation in the experiencing of and response to trauma; will help us avoid committing a "symptom error," an "abstraction error," when assessing those symptom dimensions across cultures.

\section{References}

Hartmann, Ernest

1998 Dreams and Nightmares: The Origins and Meaning of Dreams. Cambridge, MA: Perseus.

Good, B.J.

1994 Medicine, Rationality, and Experience: An Anthropological Perspective. Cambridge, UK: Cambridge University Press.

Hinton, D.E., M.H. Pollack, and L. Nguyen

2007 Orthostatic Panic as a Key Vietnamese Reaction to Traumatic Events: The Case of September 11th. Medical Anthropology Quarterly 21: 81-107.

Hinton, D.E., D. Howes, and L.J. Kirmayer

2008 Towards a Medical Anthropology of Sensations: Definitions and Research Agenda. Transcultural Psychiatry 45: 142-162.

Hollan, Douglas

2003 Selfscape Dreams. In Dreaming and the Self: New Perspectives on Subjectivity, Identity, and Emotion. Jeannette M. Mageo, ed., pp. 61-74. New York: State University of New York.

Kirmayer, L.J.

1996 Confusion of the Senses: Implications of Ethnocultural Variations in Somatoform and Dissociative Disorders. In Ethnocultural Aspects of Posttraumatic Stress Disorder: Issues, Research, and Clinical Applications. A.J. Marsella, M.J. Friedman, E.T. Gerrity, and R.M. Scurfield, eds., pp. 131-164. Washington, DC: American Psychological Association.

Kleinman, A., and J. Kleinman

1985 Somatization: The Interconnections in Chinese Society among Culture. In Culture, Depression: Studies in the Anthropology, Cross-cultural Psychiatry of Affect, Disorder. A. Kleinman and B.J. Good, eds., pp. 429-490. Berkeley: University of California Press.

Lohmann, Roger Ivar, ed.

2003 Dream Travelers: Sleep Experience and Culture in the Western Pacific. New York: Palgrave.

Mageo, Jeannette Marie, ed.

2003 Dreaming and the Self: New Perspectives on Subjectivity, Identity, and Emotion. New York: State University of New York Press. 